\title{
Global Tribology Summit Editorial
}

\section{Editorial}

Edwin P. Su, MD

Received: 13 September 2016/1 November 2016/Published online: 5 December 2016

(C) Hospital for Special Surgery 2016

Tribology is the science that explains the interaction between two sliding, moving, or rotating material surfaces. As such, it is an integral part of total joint arthroplasty, governing the performance, wear properties, and ultimate longevity of an artificial joint.

Tribology is a concept that the total joint surgeon uses on a daily basis as we perform joint arthroplasty, but is often taken for granted. We naturally assume that the materials in the artificial joint have been optimized for a patient's function and for its own longevity. However, surgeons have the ability to affect tribology and a joint replacement's outcome by altering bearing materials, head size, method of fixation, and of course, surgical implantation. How often do we actually consider the choices we make and the effect on our patients?

Thus, both surgical and material factors affect how a hip or knee implant functions for a patient. As such, both the surgeons who implant devices and the engineers who design them should have a constant discourse in order to better understand the tribology of hip and knee prostheses. We designed such a forum, the "Global Tribology Summit," held in Paris (2015) and London (2016), which brought together over 100 international orthopedic surgeons and biomechanics engineers, to discuss topics in hip and knee arthroplasty. We wanted to memorialize some of the seminal presentations from this summit in a collection of papers published in this issue.

The material presented discusses varied tribologic topics including results of different bearing materials in hip and knee arthroplasty, the emerging issue of corrosion in total hips, designing the next generation resurfacing device, the possibility of allergic responses in total knee arthroplasty (TKA), and uncemented fixation for TKA.

We hope that these papers will stimulate your thinking about joint tribology and the design and surgical factors that influence the performance of an implant!

\section{Compliance with Ethical Standards}

Conflict of Interest: Edwin P. Su, MD reports personal fees from Smith and Nephew, Inc, outside the work.

Human/Animal Rights: This article does not contain any studies with human or animal subjects performed by the any of the authors.

\section{Informed Consent: N/A}

Required Author Forms Disclosure forms provided by the authors are available with the online version of this article.

Electronic supplementary material The online version of this article (doi:10.1007/s11420-016-9534-4) contains supplementary material, which is available to authorized users.

E. P. Su, MD $(\bowtie)$

Hospital for Special Surgery,

535 East 70th Street,

New York, NY 10021, USA

e-mail: sue@hss.edu

E. P. $\mathrm{Su}, \mathrm{MD}$

Weill Cornell Medical College,

1300 York Ave,

New York, NY 10065, USA 